\title{
ENTRE LA INCERTIDUMBRE Y LA INDETERMINACIÓN. PARA UNA DIALÉCTICA DE LA ACCIÓN POLÍTICA A PARTIR DE MERLEAU-PONTY, HORKHEIMER Y ADORNO.
}

\author{
Emiliano Gambarotta \\ Universidad Nacional de La Plata - CONICET, Argentina
}

\begin{abstract}
Resumen.- Este escrito busca articular una concepción de la acción política a través de un punto de vista dialéctico. Con este fin, se parte de un primer planteamiento del problema en base a la obra de Claude Lefort, para luego indagar densamente los posibles vínculos entre la perspectiva desarrollada por Maurice Merleau-Ponty y la elaborada en colaboración por Max Horkheimer y Theodor W. Adorno. Es en el poco frecuentado entrelazamiento de dichos trabajos que, como se pretende señalar en este artículo, surge una aproximación crítica a la acción política, centrada en lo que aquí se denomina su dialéctica aporética.
\end{abstract}

Palabras clave.- Acción política, dialéctica, incerteza, Merleau-Ponty, Horkheimer, Adorno.

Abstract.- This paper seeks to articulate a conception of the political action through a dialectical point of view. For this, it begins with a first exposition of our problem through Claude Lefort's work. Then, the paper analyzes in depth the possible links between Maurice Merleau-Ponty's perspective and the one elaborated by Max Horkheimer and Theodor W. Adorno in collaboration. It is in the not so frequently studied of this two works that we can find a critical approximation to the political action, as the paper wants to show. One centred in what we call here its aporetic dialectic.

Keywords.- political action, dialectic, uncertainty, Merleau-Ponty, Horkheimer, Adorno.

En los escritos de Claude Lefort puede hallarse la recurrente aseveración de que la sociedad democrática ve amenazado su fundamento por los posibles avances de la lógica propia de la sociedad totalitaria. Esta problemática es la que pone en movimiento las presentes reflexiones en torno a las tensiones que atraviesan la constitución de lo político, de la forma en que una sociedad se da un orden a sí misma; para, sobre ese trasfondo, delinear algunos rasgos claves de una concepción de la acción política, a partir de una consideración dialéctica de la misma. Con este fin se abordarán dos perspectivas enmarcadas en tradiciones diferentes, pero que hacen de la dialéctica un pilar clave sobre el cual elevar su edificio teórico. Nos referimos, por un lado, al pensamiento desarrollado por Maurice Merleau-Ponty y, por el otro, a las reflexiones conjuntas llevadas a cabo por Max Horkheimer y Theodor W. Adorno. Así, los aportes que este escrito pretende realizar se dirigen en dos direcciones simultáneas, plan- 
teando un diálogo entre uno de los autores de la vertiente francesa del pensamiento dialéctico y una de las concepciones de raíz alemana de la dialéctica, diálogo que no suele ser visitado por la bibliografía sobre el tema. A lo cual se agrega que es en el cruce de esas perspectivas donde hunde sus raíces la concepción de la acción política que aquí se propone, centrada en lo que llamaremos su dialéctica aporética.

Es en el marco dado por tales objetivos que la concepción lefortiana acerca de las características propias de las formas de sociedad que emergen de la abolición de los referentes de certeza (del monoteísmo valorativo weberiano), con la indeterminación que ello genera, nos brindará un primer encuadre general en el cual asentar nuestro problema [1]. Esto nos llevará a rastrear las raíces de esta concepción en el pensamiento hiperdialéctico y sobrerreflexivo de MerleauPonty, para quien es nuestra vida en pluralidad la que genera la indeterminación de la acción, imposibilitando a su vez la constitución de un saber cerrado [2]. Llegados a este punto, nos remontaremos hasta la obra del propio Weber, pues encontramos allí un sendero a partir del cual dar cuenta del proceso que impulsa la clausura (totalitaria) del politeísmo valorativo [3]. Y es ese sendero el que nos conducirá a indagar la crítica al saber poder ilustrado, llevada a cabo por Horkheimer y Adorno [4]. Para así, finalmente, destacar la complementariedad de estos desarrollos en torno a la dialéctica con vistas a dar cuenta de la forma en que una sociedad se da un orden a sí misma [5], y a aprehender las características de aquello que cabe llamar una dialéctica de la acción política [6].

\section{La disolución de los referentes de certeza}

La cuestión de la democracia es una de las preocupaciones centrales que atraviesan al pensamiento de Lefort, la cual es abordada, casi constantemente, en un contrapunto que la sitúa «sobre el telón de fondo del totalitarismo»; permitiendo ello aprehender las particularidades de una a partir de su contraste con el otro, y viceversa. En tanto ambas formas de sociedad surgen de la abolición de «toda referencia a poderes sobrenaturales, o a un orden del mundo» ${ }^{2}$ a partir del cual regular las relaciones sociales; pero reaccionan de manera antagónica ante dicho fenómeno. En definitiva, emergen de una situación en la que «las diversas esferas de valores del mundo se encuentran en conflicto irreconciliable», ${ }^{3}$ pues -al decir de Weber- vivimos en un mundo habitado por una pluralidad de dioses de los valores, sin que sea posible establecer un absoluto

\footnotetext{
${ }^{1}$ Claude Lefort, "La cuestión de la democracia», en La incertidumbre democrática, Barcelona, Anthropos, 2004, p. 43. Ya en este punto puede encontrarse la deuda que tiene su pensamiento con la obra de Merleau-Ponty, pues éste señala que aquello que percibimos está siempre sobre un fondo, que "forma siempre parte de un "campo"» (Merleau-Ponty, M., La fenomenología de la percepción, México, Fondo de Cultura Económica, 1957, p. 4.). Siendo esa relación lo que permite que sea perceptible al haber algo detrás sobre lo cual destacarse.

${ }^{2}$ Claude Lefort, «La lógica totalitaria», en La incertidumbre democrática, op. cit., p. 234.

${ }^{3}$ Max Weber, «La ciencia como vocación», en Ciencia y política, Buenos Aires, Centro Editor de América Latina, 1991, p. 103.
} 
trascendente que fije una única dirección para las conductas humanas. Por lo que no queda más que la irreconciliable lucha entre los desencantados dioses, lo cual constituye el centro de la concepción weberiana de lo política en la sociedad moderna.

En este marco Lefort concibe a la democracia y al totalitarismo como cara y anverso del proceso desatado por este fenómeno. Pues mientras la primera acoge la profunda incertidumbre que implica la no existencia de un referente último de valor, el segundo rechaza todo indicio de una diferencia de cosmovisiones a su interior, pero no se funda para ello en un referente externo sino en la negación radical de toda exterioridad y la concentración en un único punto de «todas las fuerzas de la sociedad». ${ }^{4}$ En efecto, si la abolición de los referentes últimos de certeza conlleva, en última instancia, una mutación en el estatuto del poder, por la que el lugar de éste es un lugar vacío, sin que se instituya centro alguno en la sociedad capaz de asirla por completo; la sociedad totalitaria se caracteriza por ser aquella que niega esta distinción simbólica, presentándola a un punto del denso entramado social como cristalización de la identidad toda de esa sociedad y, por tanto, capaz de regular las diversas relaciones que tienen lugar en las diversas esferas sociales. Por lo que se niega la posibilidad de que exista algún exterior a lo social y, concomitantemente, al poder que se presenta como encarnación de éste. De allí que, según Lefort, esta forma de sociedad esté basada «en una lógica de la identificación ${ }^{5}$ que iguala lo distinto borrando las diferencias, señalando un único dios al cual destinar nuestras libaciones; proceso de identificación que niega a la división como elemento constitutivo de lo social, y cuyo resultado no puede ser más que el uno, que la unidad sin divisiones a la que todo se reduce.

Así, la figura social en la que se cristaliza la encarnación de ese uno se inviste, por ello mismo, de un poder ilimitado para actuar en dicha sociedad; ligado a lo cual se encuentra la pretensión de poseer un saber para el cual la sociedad es transparente, es decir: un saber absoluto. De allí que en la sociedad totalitaria, articulada en base a un poder ilimitado que sustenta un saber absoluto, que permite el ejercicio de un poder ilimitado, «lo desconocido, lo imprevisible, lo indeterminable son las figuras del enemigo". ${ }^{6}$ Pues en ellos emerge un otro (u otros) distinto y que, como tal, solamente puede ser externo a esta sociedad sin divisiones internas. Es decir, un otro que no es nunca un semejante sino la figura del enemigo que ataca la unidad de la sociedad, que con su mera existencia relativiza aquello que se pretende absoluto y que, por tanto, debe ser eliminado.

\footnotetext{
${ }^{4}$ Claude Lefort, La lógica totalitaria, op. cit., p. 233.

${ }^{5}$ Claude Lefort, «¿Renacimiento de la democracia?», en La incertidumbre democrática, op. cit., p. 263.

${ }^{6}$ Claude Lefort, La lógica totalitaria, op. cit., p. 237 (las cursivas son nuestras).
} 
Por el contrario, en la sociedad democrática no sólo se tolera la división interna sino que ésta es «constitutiva de la unidad misma de la sociedad». ${ }^{7}$ En efecto, la competencia que en ella se da, para acceder a los mecanismos de ejercicio del poder político, torna visibles las divisiones propias de una sociedad que al ser democrática las acoge y no intenta eliminarlas. En este sentido podemos hablar de una institucionalización del conflicto -no sólo en el ámbito de la política sino en todas las esferas sociales- como una de las características centrales de este tipo de sociedad; lo cual supone que el lugar del poder permanece vacío, sin que el mismo sea incorporado por alguna figura social. Por lo que esta sociedad no es transparente para sí misma, sino que mantiene zonas de opacidad que inhabilitan la erección de un saber que se pretenda absoluto y definitorio de los marcos que deben regular las interrelaciones humanas. Sobre esta base, que trunca la posibilidad de una lógica de la identificación que se cierre en el uno, es posible -o, mejor dicho, no es posible no- reconocer a los otros como semejantes que, aun cuando posean una perspectiva distinta a la mía, no puedo tachar de falsa al no haber una verdad última en la cual apoyarnos para resolver el conflicto. De allí que, con Lefort, podamos concluir que lo esencial «es que la democracia se instituye y se mantiene por la disolución de los referentes de certeza»; estableciéndose así "una indeterminación última [...] respecto al fundamento de la relación del uno con el otro en todos los registros de la vida social»». ${ }^{8}$ Indeterminación que diluye cualquier posibilidad de fijar como ya sabido lo que aun no ha tenido lugar; de allí que, para este autor, la democracia sea la sociedad histórica por excelencia, pues en ella se mantiene abierto el sentido último de los acontecimientos. En oposición, nuevamente, a lo que ocurre en la sociedad totalitaria, la cual al estructurarse "contra esta indeterminación, pretende detentar la ley de su organización y de su desarrollo, y se dibuja secretamente en el mundo moderno como sociedad sin historia». ${ }^{9}$

Llegamos así a un punto en el cual se evidencia la centralidad, en los trabajos de Lefort, de la concepción de los procesos socio-históricos como indeterminados y su importancia hermenéutica para comprender las sociedades modernas. A la vez que será el acogimiento o rechazo de la incerteza que esto produce, lo que marcará la diferencia clave entre ambas formas de sociedad. De allí que quepa profundizar en dicha concepción, para lo cual -y siguiendo lo que el propio Lefort plantea ${ }^{10}$ - indagaremos en la perspectiva de Merleau-Ponty, dedicándole a ello la próxima sección.

\section{Indeterminación de la acción, incerteza del saber}

\footnotetext{
${ }^{7}$ Claude Lefort, La cuestión de la democracia, op. cit., p. 49.

${ }^{8}$ La cuestión de la democracia, p. 50.

${ }^{9}$ Idem, p. 46.

${ }^{10}$ Cf. Idem, p. 51.
} 


\subsection{Pluralidad e incerteza}

En el pensamiento de Merleau-Ponty la indeterminación de la acción y la incerteza en el saber ocupan un papel protagónico, impregnando su concepción de la dialéctica. En efecto, según él, sólo hay dialéctica (y por ende sólo hay historia) en ese espacio en que se da la convergencia de los sujetos, en «su residencia común, el lugar de sus intercambios y de sus interacciones recíprocas", ${ }^{11}$ en donde se entretejen las propias acciones y percepciones con las de los demás, conformando la densa trama de lo social. En ella todos estamos ligados, mas no por ello viendo las cosas de la misma forma; la visión que yo tengo desde mi punto de vista, no es la misma que otro vidente tiene sobre el mismo visible. En esta relación «uno de mis visibles se hace visor», mirando las mismas cosas que yo, que soy el único en verlas «pero que también él, desde ahora, será el único en ver a su manera». ${ }^{12}$ La mera existencia de tales visiones señala los límites de mi punto de vista, al poner de manifiesto que tenemos distintas maneras de ver aquello, en lo que ambos estamos implicados, integrando así un sistema con múltiples entradas a lo mismo.

Denso entramado de relaciones en que sujetos distintos entre sí conforman un todo, que no es el agregado de parcialidades inconexas sino la coexistencia de esas parcialidades y de los lazos que entre ellas se tejen. Lo social es concebido, entonces, como «un espacio de horizontes intersubjetivos compartidos que constituyen el todo en un contexto de pluralidad». ${ }^{13}$ Siendo la dialéctica el pensamiento que está situado en ese todo, lanzando desde allí su visión a los procesos socio-históricos; capaz de captar los sentido «objetivos» de la acción humana que, en su entrelazarse con las acciones de otros, tejen procesos cuyas consecuencias (no buscadas diría Weber) escapan a la vista de quienes los generan. Un pensamiento situado en un punto de vista que lo habilita a «superar las perspectivas provisorias y parciales restituyendo la intención anónima ${ }^{14}$ que se teje en la pluralidad.

A partir de esto Merleau-Ponty plantea la posibilidad de captar un sentido en la historia, pero éste se «constituye en contacto con la contingencia» ${ }^{15}$ producto de la iniciativa humana, lo cual dota a la historia tanto de un espesor propio como de un transcurrir azaroso que no es subordinable a alguna forma de astuta razón. Por lo que esto no implica agotar el conocimiento sobre este objeto, ya que, al estar constituido por la densa trama de interrelaciones entre una pluralidad de sujetos, en él cada decisión abre sentidos nuevos que imposibilitan cualquier pretensión a un conocimiento cerrado, capaz de fijar con certeza un único sentido de la historia y de su desarrollo.

\footnotetext{
${ }^{11}$ Maurice Merleau-Ponty, Las aventuras de la dialéctica, Buenos Aires, Leviatán, 1957, p. 228.

${ }^{12}$ Maurice Merleau-Ponty, «Prefacio» a Signos, Barcelona, Seix Barral, 1964, pp. 23-24.

${ }^{13}$ Martín Plot, El kitsch político, Buenos Aires, Prometeo, 2003, p. 27.

${ }^{14}$ Maurice Merleau-Ponty, Las aventuras..., p. 18.

${ }^{15}$ Idem, p. 21.
} 
En este marco, él concibe a la historia como «relaciones entre personas adormecidas y coaguladas en las "cosas" "; ${ }^{16}$ relaciones que están cargadas del azar que surge de las decisiones humanas y su denso entrelazamiento. Por lo que, en los procesos socio-históricos, solamente podemos vislumbrar las tendencias que ellos parecen entrañar; "y esto sucede no porque carezcamos de un conocimiento suficiente, sino porque ese modo de existencia es esencial al acontecimiento humano». ${ }^{17}$ Así, el contexto de pluralidad de lo social, y la aceptación de sus consecuencias para el saber generan la imposibilidad de establecer un único punto de vista desde el cual alcanzar un conocimiento acabado, no sólo en tanto que completo sino también en cuanto que finalizado, cerrado; el cual no es otra cosa más que la imagen de una visión absoluta capaz de des-cubrir absolutos, sin dejar lugar para otras perspectivas que, por su simple ser otras, manifiestan la relatividad de aquello que se presenta bajo esa figura.

Así, la incerteza se entrelaza con la aceptación de la otredad y es justamente esto lo que Merleau-Ponty encuentra en el pensamiento de Weber. Pues lo propio del politeísmo de valores, que éste analiza, es la no resolución del conflicto entre las diversas cosmovisiones valorativas; lo cual implica que la lucha, que dicho conflicto entraña, se mantiene abierta (y constante) en tanto no se reconoce una verdad última que reúna las visiones distintas en una unidad indiferenciada en su interior, borrando aquello que pueda originar una mirada otra de lo mismo. Es por ello que, si la política es la esfera por excelencia en la que se ponen en juego las propias cosmovisiones, entonces toda política es lucha y violencia. Y aquello que Merleau-Ponty llama el «liberalismo heroico» de Weber consiste justamente en admitir esta problemática, sin buscarle falsas soluciones que pongan fin al conflicto, en situarse en un punto de vista que «hace entrar en su mismo universo aquello que lo niega, y sólo se encuentra justificado ante sus propios ojos a condición de comprenderlo". ${ }^{18}$ Ya que, para MerleauPonty, negar al otro (haciendo de él un enemigo) no puede dejar de impactar en mi propia persona, pues me hallo entrelazado con él, coexistiendo en una residencia común en la que se entretejen nuestros devenires. En este espesor de la carne de lo social «nadie es sujeto y libre sólo, [...] las libertades se contrarían entre sí y se exigen unas a las otras». ${ }^{19}$

Sobre esta base se funda el acogimiento de la profunda indeterminación en la historia, producto de la pluralidad de acciones humanas que en ella se entrelazan y de las consecuencias inesperadas que éstas acarrean. De allí que, refiriéndose al pensamiento de Hegel, Merleau-Ponty remarque esa visión de la historia como un movimiento "sin más guía que su propia iniciativa y que sin

\footnotetext{
${ }^{16}$ Idem, p. 80.

${ }^{17}$ Idem, p. 62, nota 29

${ }^{18}$ Idem, p. 251.

${ }^{19}$ Idem, p. 229 (la cursiva es nuestra).
} 
embargo no escapa fuera de sí mismo ${ }^{20}$ hacia algún tipo de trascendente suprahumano o de ley inscripta en las cosas. Esa forma de movimiento, esa manera de ser siendo, es lo que él llamará el fenómeno de la expresión; en el cual yo que me expreso y aquél a quien me dirijo estamos ligados sin concesión. Ya que mi expresión queda sometida al juicio de ese otro que vale tanto como yo, que es un semejante al que yo he elegido como tal. A quien tengo que comprender (y no negar) si aspiro a no ser negado a mi vez; estableciendo un camino entre nuestras vidas entrelazadas, y esto es expresarme.

\subsection{La expresión y su estilo}

Expresión en la que mis propias acciones, mis propias palabras exceden los límites de lo que yo, como ego, me propongo expresar. Las consignas que yo me quiero dar se ven rebasadas, y esto genera una inauguración de sentido que desborda la existencia fáctica del acto, un advenimiento que constituye lo propio del orden de la cultura (del orden humano). Frente a lo existente, a lo ya instituido, la expresión (sea ella acción, palabra o mero gesto) con el advenimiento que ella entraña instituye algo nuevo; por ello, en el silencio de lo ya dicho, la palabra originaria es un «acto instituyente que dice lo nunca antes dicho y actúa lo nunca antes actuado". ${ }^{21}$ Dotando de sentido, con su realización, a aquello que antes de ella aparecía como informulado e informulable; pues es un tantear "en torno a una intención de significar que no se guía por un texto, que precisamente está escribiéndolo".$^{22}$ Sin embargo ello no implica que la expresión sea una suerte de creación ex nihilo, antes bien es el comienzo de algo nuevo pero también una continuación, una reanudación constante de los intentos de expresión que hace a cada una de ellas cómplice de las que le antecedieron mas también de las que le sucederán. De allí que Merleau-Ponty sostenga que es posible encontrar una vinculación entre la pluralidad de expresiones que inauguran sentido a lo largo del tiempo, captándose a la historia como «la tentativa continuada de la expresión», ${ }^{23}$ en la que lo nuevo y lo viejo se hilvanan entre sí en ese denso entramado que constituye la carne de lo social.

Ahora bien, para romper ese silencio es necesario encontrar la propia voz, esa forma de decir las cosas que no repite lo ya dicho sino que es mi manera de hablar. Y es en este punto que se hace necesario introducir una noción central en el pensamiento de Merleau-Ponty: la de estilo; que es aquello que se pone en la expresión, que la carga con mi particular forma de percibir el mundo (y a los otros en él), de dotar de sentido a lo que en él acaece y a aquello que a través mío adviene a él. A la vez que, desde cierto ángulo, es lo que permite la expresión al ser la fórmula desde la que formulamos aquello que expresamos;

\footnotetext{
${ }^{20}$ Maurice Merleau-Ponty, «El lenguaje indirecto y las voces del silencio», en Signos, op. cit., p. 86.

${ }^{21}$ Martín Plot, op. cit., p. 23.

${ }^{22}$ Maurice Merleau-Ponty, El lenguaje indirecto..., op. cit., p. 57.

${ }^{23}$ Idem, p. 83.
} 
el estilo como un esquema interior a través del cual establecemos una particular relación con el ser, una singular manera de vivir en él, de actuar e interpretarlo. Un modo de poner en forma el ser que hace emerger sentido de un mundo que no lo posee con independencia de él, que no lo tiene con anterioridad o de manera ajena a su interrelación con el estilo.

De allí que se lo pueda concebir como una «potencia general de formulación», ${ }^{24}$ que está imbricado en (ó detrás, ó sosteniendo, ó sobre) nuestra capacidad de producir algo nuevo, rompiendo el cíclico círculo de la mera reproducción de lo existente. Sin embargo, este generar algo nuevo responde a un esquema (interior), es una puesta en forma que mantiene una cierta constancia entre sus distintas realizaciones particulares; cargando nuestras expresiones con un mismo estilo, que es también lastrarlas con lo viejo aun allí donde inauguran un nuevo sentido. A través de él, entonces, se establece una particular manera de relacionarse con el mundo social, manera que me diferencia del modo en que los otros lo hacen; a la vez que me enlaza a ellos, al desbordarme el sentido, el cual se constituye en el contexto de la pluralidad.

Estilo que no es un mero automatismo, una reacción «mecánica» a los estímulos inscripta en la materialidad del ser humano, concebido así como una suerte de objeto. Pero tampoco es el producto de un ego «consciente» que, antes de actuar (o de expresarse), analiza las condiciones en que va a realizar su acción para, a partir de ello, calcular cuál será la mejor estratagema a poner en práctica. El estilo entonces no es propiedad ni de un puro objeto ni de un puro sujeto, sino que en cierta forma es algo de los dos, sin resolver la tensión entre ambos polos. En definitiva, el estilo está inscripto en nuestro cuerpo, en ese «sistema de sistemas consagrado a la inspección de un mundo»; ${ }^{25}$ punto de confluencia de nuestra manera de ver, de tocar, de hablar, ligazón última que entraña y reúne todo ello y más en la fórmula general de formulación que es nuestro estilo.

Y es este buscar el entrelazamiento entre sujeto y objeto, antes que la petrificación de su oposición, lo que Merleau-Ponty va a encontrar en al teoría de la praxis desarrollada por Lukács. La cual entraña, según aquél, un esquema de existencia que es «algo menos que un sujeto y más que un objeto», ${ }^{26}$ por lo que conlleva el rechazo, desde una posición marxista, de las alternativas del marxismo entre un voluntarismo subjetivista y un objetivismo que aguarda la maduración de las condiciones materiales. Se deja atrás al pensar maniqueo pero también se supera el relativismo al penetrar profundamente en él, al internarnos en la tensión siempre abierta de la adherencia entre sujeto y objeto, de la carne; superación que «dejaría de existir si se erigiera lo relativo en absoluto». ${ }^{27}$ Merleau-Ponty nos propone así una perspectiva relacional pero de rela-

\footnotetext{
${ }^{24}$ Idem, p. 78.

${ }^{25}$ Idem, p. 79.

${ }^{26}$ Maurice Merleau-Ponty, Las aventuras..., op. cit., p. 56.

${ }^{27}$ Idem, p. 66.
} 
ciones reversibles, cuyo prototipo encontramos en aquella relación en la que el sujeto en tanto encarnado es un objeto que en tanto capaz de expresarse es sujeto (que en tanto encarnado es objeto). Y es esta «reversibilidad [la] que define la carne»; ;8 mas ella no se realiza nunca completamente, no se alcanza una coincidencia final que sería también fin de la relación de reversibilidad y de su irresoluble e inestable tensión.

\subsection{Dialéctica, hiperdialéctica y revolución}

El pensamiento capaz de dar cuenta de este complejo entramado de relaciones reversibles es, según Merleau-Ponty, la dialéctica; pues ella admite que cada uno de los términos de una relación sólo llega a ser lo que es gracias al movimiento que lo lleva al término opuesto. Sin embargo, afirmar que este desarrollo conduce a un punto que es la superación de todas las contradicciones, no es para él más que una ilusión que intenta ponerle fin al movimiento propio de los procesos socio-históricos y con éste a la historia. Por lo que, no es un pensar dialéctico a secas lo que este autor propone, sino un modo de concebir a la dialéctica que se opone a «la pretensión de darle término en un fin de la historia, o en una revolución permanente». ${ }^{29}$ Merleau-Ponty, en definitiva, excluye de su pensar dialéctico la idea de un negativo puro, que como negación de todo y fundamentalmente de sí mismo, no tracciona ya hacia una nueva negación; o, para decirlo con mayor precisión, que se presenta como no dejando espacio alguno desde el cual pueda surgir una nueva negación, pues tal posibilidad haría visible la impureza de la anterior negación, su ambigua relatividad.

Es frente a esa dialéctica «cerrada» que él elabora una dialéctica «abierta», ${ }^{30}$ que no sólo dirige su crítica al mundo sino que también la emplea para interrogarse a sí misma, que es en definitiva una «hiperdialéctica». La cual no busca resolver la tensión entre los términos en pos de una identidad final (como es posible hallar incluso en el pensamiento lukacsiano), sino que, por el contrario, «plantea sin restricción la pluralidad de las relaciones y lo que se ha llamado ambigüedad». ${ }^{31}$ Ausencia de identidad final que implica remover el fundamento sobre el que, la «mala dialéctica», pretende construir un saber absoluto en el que el todo se vuelve transparente para sí mismo; estableciéndose así como perspectiva única que, al superarlas, elimina el resto de las posibles visiones sobre el mundo. A la vez que la claridad de la transparencia hace superflua la continuidad de la interrogación frente a algo que ya es completamente claro. No hay lugar para una nueva negación, para la pervivencia de una mirada crítica. Frente a esto, el pensamiento de Merleau-Ponty se reconoce como hiperdialéctico y, complementariamente, sobrerreflexivo; es decir que acoge en su visión la existencia de una zona de opacidad, de un resto invisible que al no ser iluminable mantiene siempre presente un ámbito de oscuridad, de incerte$z a$. De allí la imposibilidad de suspender la interrogación sobre el mundo que

\footnotetext{
${ }^{28}$ Maurice Merleau-Ponty, Lo visible..., op. cit., p. 179.

29 Maurice Merleau-Ponty, Las aventuras..., op. cit., p. 230.

30 Éste es uno de los puntos nodales a partir de los cuales pueden pensarse las cercanías de este autor con el pensamiento de Horkheimer y Adorno, así, por ejemplo, en referencia a este último Schwarzböck caracteriza a su pensamiento como una «dialéctica abierta» (Cf. Silvia Schwarzböck, Adorno y lo político, Buenos Aires, Prometeo Libros, 2008, p. 30; y también Silvia Schwarzböck, "El reino de los medios", en Deus Mortalis, № 2, 2003).

${ }^{31}$ Maurice Merleau-Ponty, Lo visible..., op. cit., p. 122.
} 
habitamos, sobre la dialéctica con la que, junto con Merleau-Ponty, lo pensamos.

Es sobre esta base que se asienta la crítica de este autor a la figura de la revolución, a la concepción de la acción política que ella entraña, crítica que se puede sintetizar en la expresión según la cual «en su manera de negar ya está presente su manera de afirmar». ${ }^{32}$ En efecto, en esta relación de reversibilidad el régimen revolucionario se presenta como una negación de sí mismo, generando la imagen de no tener necesidad de un exterior desde el cual ser negado y, en última instancia, de no tener exterior alguno; no hay nada por fuera de él, no puede haberlo, pues ello implicaría la posibilidad de una nueva negación que continúe la historia a la que la revolución vino a poner fin. En este sentido la revolución (pero también muchos de los momentos de la tradición marxista, en la que Merleau-Ponty rastrea la existencia de esta misma limitación) «se presenta como el asiento de un saber absoluto ${ }^{33}$ en el cual funda su ejercicio de un poder absoluto, cancelándose la indeterminación de la acción junto con la ausencia de certeza en el saber.

A su vez, y siguiendo esta misma lógica, aquello que se muestra como concentración de la negatividad toda, del sentido que se ha venido desplegando a lo largo de la historia y cuya realización pondría fin a todo el proceso anterior, no puede tener oposición; todo punto de vista distinto es una exterioridad no tolerable por aquello que se pretende absoluto. De allí que «todo cuanto es extraño es enemigo" ${ }^{34}$ y en tanto que tal debe ser eliminado. Se evidencia aquí la estrecha relación entre este análisis y la forma en que Lefort presenta a la sociedad totalitaria, particularmente al lugar que en ella ocupan los otros (inexistentes en el interior; enemigos y no semejantes en un exterior a ser eliminado). Es por todo esto que, para Merleau-Ponty, la acción revolucionaria está condenada al fracaso en su triunfo; pues alcanzar sus objetivos y conseguir instituirse en un régimen que institucionaliza la crítica es ya perder la capacidad crítica (especialmente la autocrítica), al pensarse a sí misma como el universal que se ha concretado no permite que haya espacio para particulares que no se unifiquen en la identidad identificante de una lógica que se devora las diferencias. Es por ello que "la revolución y su fracaso serían la misma cosa», ${ }^{35}$ ya que ella porta una negación extrema que lleva «adherida» -en una relación de reversibilidad- una afirmación extrema, la cual no deja lugar alguno a la pluralidad humana.

\footnotetext{
${ }^{32}$ Maurice Merleau-Ponty, Las aventuras..., op. cit., p. 258.

${ }^{33}$ Idem, p. 98.

${ }^{34}$ Idem, p. 231 (las cursivas son de Merleau-Ponty).

${ }^{35}$ Idem, p. 244.
} 


\section{Weber como gozne}

Después de este recorrido podemos volver sobre nuestros pasos a fin de reconfigurar, a la luz de estos elementos, los problemas que este escrito se ha propuesto abordar. Hemos visto que, según Lefort, la sociedad democrática se define por ser aquella que acoge la indeterminación producto de la abolición de los referentes de certeza, permitiendo así la institucionalización del conflicto, la aceptación -convertida en institución social- de la imposibilidad de resolver el politeísmo valorativo y la lucha que este entraña. Por lo que en ella se preserva la humana pluralidad de los puntos de vista, la copresencia de visiones opuestas, de una oposición sin la cual no habría dialéctica o, lo que es lo mismo, no habría historia. Ahora bien, si la sociedad democrática es aquella capaz de acoger la profunda indeterminación de la carne de lo social, entonces ¿por qué se ve, según Lefort, constantemente amenazada por el totalitarismo? ¿Qué lleva a que el totalitarismo dé «una respuesta a los interrogantes planteados por la democracia", que exista ese intento por "desterrar la indeterminación que acosa a la experiencia democrática» ${ }^{36}$ En última instancia, ¿qué procesos socio-históricos se inscriben en ese mismo plexo relacional, en esa carne de lo social, y pueden dar cuenta de la sostenida amenaza totalitaria a esa incertidumbre? ${ }^{37}$

Abordar esta problemática nos permitirá avanzar también en una segunda cuestión, que parte de la concepción merleau-pontiana de la revolución como una acción política de extrema radicalidad en su pureza, en al menos tres aspectos: la radicalidad de la negación que entraña y de la afirmación a ella adherida; la radicalidad de la ruptura con el pasado que pretende instaurar, al presentarse como cerrando un ciclo histórico (el de la pre-historia) para dar comienzo a una sociedad completamente nueva; la radicalidad del saber (absoluto) y la del poder (también absoluto) que sobre él se erige, instrumentos a través de los que se llevará a cabo la pretensión de rehacer la historia. Ahora bien, la lógica con la que Merleau-Ponty piensa y critica a esta extrema forma

${ }^{36}$ Claude Lefort, «La imagen del cuerpo y el totalitarismo», en La incertidumbre democrática, op. cit., pp. 255-256.

${ }^{37}$ Una pregunta muy similar podría hacérsele a Laclau y Mouffe, en tanto su consideración de «la apertura de lo social como constitutiva, como "esencia negativa" de lo existente» (Ernesto Laclau y Chantal Mouffe, Hegemonía y estrategia socialista, Buenos Aires, FCE, 2006, p. 132) no sólo es cercana al punto de vista lefortiano que hemos presentado, sino que incluso ellos retoman explícitamente su planteo (Cf. Idem pp. 232-233). Sin embargo, es dable señalar una diferencia fundamental entre ambas concepciones, pues mientras que para Lefort esta apertura de lo social está ligada a la instauración de un politeísmo valorativo producto del fin de los regimenes teológico políticos (que tiene una particular cristalización en la decapitación del Rey durante la Revolución Francesa, Cf. Claude Lefort, La imagen del cuerpo..., op. cit., pp. 252254), en Laclau y Mouffe no es el resultado de un particular proceso socio-histórico, sino una característica ontológica de lo social. Esto introduce una diferencia de estatus clave en el pensamiento de estos autores, ya que la imposibilidad de constituir una sociedad plena responde a su concepción ontológica, mientras que los esfuerzos por constituirla (por suturar la abertura) son el producto de la acción humana, que como tal está necesariamente (ontológicamente) condenada al fracaso. Lo cual hace aun más complejo dar cuenta, desde el punto de vista por ellos planteado, del por qué tendrían lugar intentos de realizar una sutura definitiva (totalitaria diríamos con Lefort) de lo social. 
de acción política ¿puede permitirnos pensar otras formas menos radicales, más ambiguos, de acción política? $\mathrm{Si}$, como hemos visto, el régimen que la acción revolucionaria instaura comparte algunas características fundamentales con la sociedad totalitaria lefortiana, la particular adherencia que es intrínseca a la acción revolucionaria ¿juega algún papel a la hora de reflexionar en torno a las acciones políticas que acaecen en el interior de lo que Lefort Ilamaría una sociedad democrática?

Las secciones anteriores nos han permitido ver que tanto Merleau-Ponty como Lefort encuentran en una particular apropiación del «liberalismo heroico» weberiano, un punto de partida en base al cual pensar la pluralidad de visiones disímiles sobre lo mismo y su consecuente conflicto. $Y$ es continuando ese movimiento, remontando el camino hasta la obra del propio Weber, que encontramos los rastros de otro sendero cuyo recorrido nos permite delinear una respuesta para los problemas que nos hemos planteado.

En efecto, en el pensamiento de Weber el conflicto y la lucha, que el politeísmo de valores genera, se ve siempre contrapesado por otro proceso socio-histórico que, antes que introducir nuevos dioses, los destierra, desencantando el mundo. Nos referimos al proceso de racionalización instrumental de las diversas esferas de experiencia de la sociedad. Así, para este autor, la política es el terreno donde por antonomasia tienen lugar las disputas de valores y el político, por ende, es la figura en la que se plasma semejante lucha (de allí que aun cuando la política se haga con la cabeza, resulta indispensable que el político posea además una "devoción apasionada a una "causa" " ${ }^{38}$ ). Sin embargo, Weber nos suele presentar a la cara del político en relación con su cruz: el funcionario; cuyo terreno de acción es la burocracia, ámbito en el cual no impera el conflicto en torno a valores, la pasión por alguna causa, sino que se desarrolla y expande la mentada lógica de racionalización o, tal y como algunos autores posteriores especificarán, de una racionalización instrumental «basada en la calculabilidad». ${ }^{39}$

Es esta lógica la que, en el pensamiento de Weber, puede considerarse como el fenómeno opuesto a la reapertura del politeísmo valorativo; pero no una oposición en la que ambos coexistan armónicamente, pues lo propio de este proceso de racionalización instrumental es tender a avanzar sobre su contrario. De allí el diagnóstico weberiano según el cual «el destino de nuestra época se halla caracterizado por una racionalización e intelectualización y, sobre todo, por el "desencantamiento del mundo". Precisamente los valores esenciales y más sublimes se han retirado de la vida pública»; ${ }^{40}$ conduciendo esto a la «fría noche polar» en la que el sol de los valores se ha ocultado. Proceso de racio-

\footnotetext{
${ }^{38}$ Max Weber, «La política como vocación», en Ciencia y política, Buenos Aires, Centro Editor de América Latina, 1991, p. 60.

${ }^{39}$ George Lukács, Historia y consciencia de clase, México, Grijalbo, 1969, p. 95.

${ }^{40}$ Max Weber, «La ciencia como vocación», en Ciencia y política, op. cit., p. 113.
} 
nalización que se despliega en las diversas esferas sociales, aun cuando sea en la relación político-funcionario donde se cristaliza de forma más evidente. Así, aun cuando el honor del funcionario esté no en fijar fines (como sí lo está el honor del político) sino en llevar a cabo correctamente aquello que le ha sido ordenado, en ser un medio eficaz y eficiente en la realización de decisiones que él no toma, Weber nos muestra en varias oportunidades como ese mismo aparato burocrático, munido con su saber técnico y el manejo minucioso de los detalles de la administración, avanza sobre las prerrogativas de los políticos y su Parlamento. ${ }^{41}$ Lo cual lleva a una progresiva pérdida del politeísmo valorativo a favor de un nuevo monoteísmo, el de una racionalidad instrumental que se muestra sino el saber sobre el cual asentar el ejercicio del poder capaz de articular lo social en su conjunto. De allí que sea en una reflexión en torno a dicha racionalidad donde busquemos respuestas a las preguntas que nos hemos formulado.

\section{El saber ilustrado y su certeza}

\subsection{La ilustración y la lógica totalitaria}

Una de las perspectivas teóricas que más ha trabajado la problemática inscripta en el avance progresivo de la racionalidad instrumental es la elaborada por Horkheimer y Adorno, particularmente en aquellos escritos realizados en estrecha colaboración en la década de 1940. Es esta mirada la que seguiremos en los próximos apartados, para a partir de ella pensar al funcionario y la lógica que su acción entraña.

Desde el inicio mismo, ellos señalan que la ilustración «ha perseguido desde siempre el objetivo de liberar a los hombres del miedo y constituirlos en señores», ${ }^{42}$ desencantando a la naturaleza a través del intelecto, para así dominarla. En el camino hacia la construcción de ese particular tipo de saber (que es un poder) llamado ciencia, los seres humanos renuncian a la captación del denso sentido del mundo en que viven; la sustitución del «concepto por la fórmula, [de] la causa por la regla y la probabilidad» ${ }^{43}$ nos brinda el prototipo

\footnotetext{
${ }^{41}$ Extendernos más sobre esta temática excedería con mucho los alcances y las intenciones de este escrito; mas cabe señalar que ella atraviesa todo el texto «Parlamento y gobierno en una Alemania reorganizada» (Max Weber, «Parlamento y gobierno en una Alemania reorganizada», en Obras selectas, Buenos Aires, Distal, 2003), particularmente su segundo capítulo que lleva el no poco sugerente título de «Poder burocrático y liderazgo político». Tal vez la imagen más clara de esta tensión entre política y burocracia se dé en el caso de la transformación antiautoritaria del carisma (donde claramente el líder carismático no autoritario se presenta como capaz de encarnar un conjunto de valores e introducirlos a la historia con su accionar) y su compleja relación con la esfera económica (en la cual predomina por excelencia, al menos en el capitalismo, la racionalidad basada en el cálculo). Al respecto véase Weber, M., Economía y sociedad, México, FCE, 1998, capítulo 3, §14, especialmente p. 216.

${ }^{42}$ Max Horkheimer y Theodor W. Adorno, Dialéctica de la ilustración. Fragmentos filosóficos, Madrid, Editorial Trotta, 2001, p. 59.

${ }^{43}$ Idem, p. 61.
} 
del proceso por el cual, en el conocimiento, avanza progresivamente una lógica calculatoria. Es en este sentido que podemos hablar de una razón depurada de sus conceptos metafísicos, de aquellas ideas a partir de las cuales se pensaban valores morales y que la vinculaban a nociones como la de libertad y justicia. La razón «simplemente ha sido reducida a su sentido instrumental de un modo más radical que nunca». ${ }^{44} \mathrm{Y}$ aquello que no se doblega a su criterio, manteniendo su diferencia, es sospechoso para la ilustración, pues, desde su punto de vista, en lo que no ha sido reducido y asimilado por ella se mantiene aun un encantamiento que es fuente de ese miedo que la ilustración pretende eliminar.

De allí que el saber ilustrado, que tiene en la técnica su esencia, se presente como un esfuerzo constante por destruir a los dioses y a las cualidades, por erradicar todo aquello que no sea sometible al cálculo, que no sea medible y deducible de los principios que definen a dicho saber. Por eso su ideal es el sistema, la construcción de un conocimiento cerrado sobre sí mismo de cuyos principios se derive toda otra afirmación, sin lugar alguno para lo distinto. Según el punto de vista de la ilustración no puede existir otra manera de ver las cosas, no puede haber otra forma de entender lo que sucede que comparta con ella la misma pretensión de verdad; toda otra perspectiva es empujada a mera superstición, a ser un discurso que nada válido nos dice acerca del mundo y cuya existencia, por ende, no tiene ningún sentido. Y es la propia mitología, en su imponerse a la más antigua fe mítica, la que «ha puesto en marcha el proceso sin fin de la ilustración, en el cual toda determinada concepción teórica cae con inevitable necesidad bajo la crítica demoledora de ser sólo una creencia»; ;5 hasta que este proceso alcanza a la propia llustración, cuyos conceptos metafísicos son positivamente reducidos a simple sinsentido. Es por esto que Horkheimer y Adorno sostienen la tesis según la cual el mito es ya ilustración; y ambos son totalitarios al no tolerar la existencia de ningún otro, ya que «nada absolutamente debe existir fuera, pues la sola idea del exterior es la genuina fuente del miedo», ${ }^{46}$ al introducir la abertura de la incerteza en el sistema que se pretende cerrado.

Esto conduce a una reificación del pensamiento ilustrado, pues su lógica abstracta -que tiene por modelo al procedimiento matemático- sólo produce formas vacías, incapaces de aprehender la concreta densidad cualitativa de los procesos que se estudian. Se produce así un dócil sometimiento de la razón a los datos inmediatos, sin que haya allí lugar para una mirada otra, que tome distancia de lo establecido. Por lo que, según los autores, el pensamiento no hace más que repetir el estado de cosas actual, haciendo de lo contingente algo necesario, de lo transitorio algo eterno; «lo que existe de hecho es justificado, el conocimiento se limita a su repetición, el pensamiento se reduce a mera

\footnotetext{
${ }^{44}$ Max Horkheimer, «Razón y autoconservación», en Teoría tradicional y teoría crítica, Barcelona, Ediciones Paidós e I.C.E. de la Universidad Autónoma de Barcelona, 2000, p. 92.

${ }^{45}$ Max Horkheimer y Theodor W. Adorno, Dialéctica de la ilustración, op. cit., p. 66.

${ }^{46}$ Idem, p. 70.
} 
tautología», ${ }^{47}$ no es otra cosa que la reiteración de proposiciones que no agregan nueva información, no dice nada nuevo, es silencio. Al igual que el mito, con su cíclico devenir, la ilustración no hace más que reproducir lo dado, y así recae en la mitología, de la cual nunca supo escapar. Esta lógica intrínseca lleva, entonces, a la erradicación de toda diferencia y de toda indeterminación; de allí que Horkheimer y Adorno sostengan que «la ilustración es totalitaria como ningún otro sistema». ${ }^{48}$

\subsection{Razón, autoconservación y sistema absoluto}

Semejante lógica abstracta impacta directamente en la forma en que los seres humanos se relacionan con los otros y consigo mismos, con su naturaleza interna; la cual ha de ser dominada -al igual que la naturaleza externa- por la fría razón instrumental. ${ }^{49}$ Pues, para la mirada ilustrada, ella debe «regular todas las relaciones entre los hombres, fundar toda actividad que se exija a los individuos, aunque sea el trabajo de esclavos». ${ }^{50}$ El ser humano no satisface sus necesidades, aun las más sencillas, sino a través de una relación mediada por diversas instancias sociales; siendo la razón instrumental la que fija el patrón con que estas humanas relaciones deben tejerse, es a través de ella que el individuo genera un equilibrio entre su propio beneficio y el de la colectividad, sin la cual él no sería nada, no podría vivir. Instauración de un equilibrio que se presenta bajo la figura de la ley (racional), ya que ella es la que debe regular las relaciones entre los individuos, buscar la armonía entre lo universal y el interés particular; quien pretenda vivir entre seres humanos debe obedecer las leyes, en esto consiste el consejo de la razón. Lo cual es igual a decir que ella nos puede pedir en todo momento que renunciemos a nuestro pensamiento, a nuestra particular manera de ver las cosas, para obedecer aquello que se considera racional. La prédica ilustrada en favor de la abjuración de nuestro propio juicio se sostiene en la racionalidad de dicha abjuración.

Es en este marco que se torna racional en pos de la propia autoconservación, que depende de la conservación de la sociedad, que el individuo se deba «hacer violencia a sí mismo. [...] Gracias a su capacidad racional de comprensión debe dominar los sentimientos e instintos contrarios. Sólo la inhibición de los impulsos posibilita la cooperación humana». ${ }^{51}$ Inhibición que el individuo debe ejercer sobre sí mismo, apoyándose en los «consejos» que la razón le da para dominar su naturaleza interna y posibilitar así la coexistencia con otros in-

\footnotetext{
${ }^{47}$ Idem, p. 80 (las cursivas son nuestras).

${ }^{48}$ Idem, p. 78. miento Crítico, Vol. 4 № 1, Año 2010.

${ }^{50}$ Max Horkheimer, Razón y autoconservación, op. cit., p. 89.

${ }^{51}$ Idem, p. 94.
}

${ }^{49}$ El lector interesado puede encontrar un desarrollo propio de esta problemática, aquí apenas esbozada, Emiliano Gambarotta, "La dialéctica aporética entre cuerpo y sí mismo: Una lectura de Dialéctica de la ilustración en clave política", en Intersticios. Revista Sociológica de Pensa- 
dividuos; lo cual paga al precio de la pérdida de su libertad, su autonomía se convierte así en heteronomía. Y cuando dicha razón se vuelve todopoderosa «nadie debe quedar fuera y poder contemplar desde allí», no debe existir ningún ser irracional capaz de arrojar luz sobre el conjunto, pues «su existencia proclama la relatividad del sistema de la autoconservación radical, que se postula como absoluto». ${ }^{52}$ Para aquellos que se atrevan a cruzar esa línea, situándose en las afueras de un sistema que no tolera afueras, hay un medio de hacer que vuelvan, que abandonen su singular manera de ver las cosas: el dolor. A través de él «se hace volver en sí a los díscolos y a los soñadores, a los fantasiosos y a los utopistas reduciéndolos a sus cuerpos, a una parte de sus cuerpos». 53

\subsection{Dialéctica aporética}

Este proceso de dominación de la naturaleza -interna y externa- que conlleva la eliminación de toda diferencia se encuentra en el centro de la consideración de los autores. Sin embargo, en todo esto no hay más que el des-cubrimiento de un sentido intrínseco a la ilustración, todavía no hay una dialéctica de la ilustración; ya que hasta aquí no hay oposición, al no haber un término contrario que mantenga una tensión con esa razón instrumental y todo lo que ella implica. En definitiva, hemos visto el avance de una cierta lógica, pero no su movimiento hacia un contrario, y de éste hacia aquella. La dialéctica aparece ante nuestros ojos cuando percibimos que esa misma razón depurada, aun tiene algo que la hace capaz de «reconocer la figura de la injusticia y la dominación», ${ }^{4}$ para así elevarse por encima de aquello que se nos aparece como una segunda naturaleza e iluminarla como eso que es: una apariencia. La razón que en algún momento tuvo la pretensión de instaurar la armonía entre los intereses particulares y los intereses generales de la colectividad, ha derivado -en tanto que justificación de la renuncia a la propia libertad- en la implantación de una lógica totalitaria, para la cual el dolor es tan sólo un medio más a ser instrumentalmente utilizado; y es ese mundo el que destruye sus ilusiones de libertad y fraternidad, pérdida que la hace capaz de reconocer la ausencia de ambas en el presente, de resistir al sistema que ni siquiera permite que alguien vea dicha ausencia. La misma ilustración lleva en su interior los elementos que permiten iluminar su propia renuncia a realizarse, que permiten criticarla.

Es sólo en este sentido que podemos hablar de su dialéctica, al percibir la tensión irresuelta entre términos opuestos. Solamente en este contexto podemos comprender el significado de la afirmación de Horkheimer y Adorno, según la cual «la praxis verdaderamente subversiva depende de la intransigencia de la teoría». 55 pues semejante intransigencia es la posibilidad de mantener vivo un

\footnotetext{
${ }^{52}$ Idem, p. 116.

${ }^{53}$ Idem, p. 117.

${ }^{54}$ Idem, pp. 118-119.

${ }^{55}$ Max Horkheimer y Theodor W. Adorno, Dialéctica de la ilustración, op. cit., p. 94.
} 
punto de vista crítico, capaz de tomar distancia de lo existente, de desnaturalizar aquello que se nos presenta como necesario y eterno, para captar así su sentido de conjunto. Es, en última instancia, preservar viva la posibilidad de un mirar desde afuera a aquello que se pretende sin exterior, iluminar su relatividad aun cuando se crea absoluto.

Así, los autores se esfuerzan por aprehender la dialéctica de la ilustración, la existencia de movimientos internos a ella, que parecen dirigirse en direcciones opuestas pero que cuando se mira al conjunto se hace visible su sentido común, su entrelazamiento. De allí que la condena del saber (que es un poder) ilustrado a la superstición -a lo no ilustrado y, por tanto, lo distinto a él- haya "significado siempre, a la vez que el progreso del dominio, también su desenmascaramiento». ${ }^{56}$ Es por esto que Horkheimer y Adorno no dudan en remarcar, desde el principio, la aporía con la que se han topado, según la cual «la libertad en la sociedad es inseparable del pensamiento ilustrado. Pero [...] el concepto de este mismo pensamiento, no menos que las formas históricas concretas y las instituciones sociales en que se halla inmerso, contiene ya el germen de aquella regresión que hoy se verifica por doquier». ${ }^{57}$ El proceso de la ilustración entraña una contradicción entre términos opuestos, que ella sostiene en forma simultánea, adheridos entre sí, y que no encuentra su resolución en una superación que dé término al proceso; estamos entonces ante una dialéctica que es ambigua y aporética.

\section{La adherencia entre la sociedad democrática y la sociedad totalitaria}

Luego de este trabajo de lectura sobre los materiales elaborados por Horkheimer y Adorno, podemos retomar las preguntas formuladas en la tercera sección de este escrito, pues su pensamiento nos permite aprehender la lógica subyacente al encumbramiento de una racionalidad instrumental -que es también un determinado punto de vista, una manera de percibir el mundo-, cuyo único objetivo es la autoconservación del individuo y de la sociedad de cuya perdurabilidad depende la vida de aquél; lo cual entraña, como hemos visto, un movimiento que tiende a la reproducción de lo existente, a la conservación del presente estado de cosas en su forma actual. Excluyendo completamente de él cualquier otra mirada que pueda introducir un sesgo de relatividad, una indeterminación que le abra la puerta a lo desconocido e incierto.

Es en el entrelazamiento de las perspectivas aquí abordadas, entonces, donde encontramos los elementos con los que dar cuenta de cómo determinados procesos socio-históricos llevan a que la sociedad democrática, tal como la concibe Lefort, se vea constantemente amenazada por un totalitarismo que viene a desterrar la indeterminación que aquella acoge. Pues en el mismo plexo relacional en que está inscripta la indeterminación propia de la acción humana, su ser producto de un punto de vista necesariamente parcial desde el momento en

\footnotetext{
${ }^{56}$ Idem, p. 92 (las cursivas son nuestras).

${ }^{57}$ Idem, p. 53.
} 
que vivimos con otros que ven lo mismo que yo pero que lo hacen a su manera, imposibilitando la obtención de una certeza acerca del sentido final que adquirirá mi propia acción sometida al juicio de los otros con los que tengo una residencia común; en ese mismo plexo relacional, decíamos, también está inscripta la tendencia a ordenar esas relaciones, a establecer los parámetros que deben ser obedecidos en pos de la autoconservación de la sociedad, obediencia que conlleva la dominación voluntaria por parte de un individuo para el cual es racional atarse con las cadenas de las leyes -así como Odiseo se ató al mástil de su nave- antes que poner en riesgo su propia autoconservación, y atar también a los demás con esas cadenas, no permitiendo que alguien quede libre de ellas.

Simplificando el argumento, para así exponerlo más claramente, cabe decir que la misma vida en conjunto, el estar entrelazados unos con otros, entraña la existencia de esa opacidad irreducible que impide el establecimiento de cualquier certeza última, de que haya una base común sobre la cual acotar el conflicto producto del politeísmo de valores; a la vez que requiere, para su perdurabilidad en el tiempo, del establecimiento de algún tipo de orden que regule los vínculos entre los seres humanos para hacer posible su convivencia. Orden que lleva en su lógica interior el germen de un rechazo extremo a cualquier perspectiva que sea externa a él, de una tendencia totalitaria que no acepta lo distinto pues eso ya es cuestionarlo. A la vez que la estructuración de dicho orden es lo que permite la vida en conjunto, el entre-nos del que emerge el contexto de pluralidad, etc. ${ }^{58}$

Esto nos lleva a considerar que las interrelaciones humanas poseen a un mismo tiempo una tendencia a la indeterminación y a la determinación, a la regulación de los modos de actuar y relacionarse. Por lo que si el ser de lo social contiene a la vez a estos dos términos opuestos, adheridos el uno al otro, y que la previsible tensión entre ellos; entonces resulta iluminador considerar los conceptos lefortianos de sociedad democrática y sociedad totalitaria no como formas concretas que se dan realmente en su existencia, sino -apelando aquí nuevamente al repertorio weberiano- como tipos ideales. ${ }^{59}$ Pues al concebirlas

\footnotetext{
${ }^{58}$ Una respuesta similar podría darse a la problemática planteada en torno a la perspectiva de Laclau y Mouffe (véase supra nota 37). Sin embargo, la diferencia de estatus que en ellos tiene la imposibilidad de la sociedad para con los intentos de suturarla lleva a que esta respuesta no sea extensible a su planteo, a la vez que nos muestra uno de sus puntos ciegos. Puesto que las prácticas articulatorias han de dirigirse en contra de lo que la propia ontología genera; por lo que aquí no hay una tensión entre dos términos opuestos y adheridos entre sí, sino las reacciones de las prácticas ante la lógica producto del fundamento ontológico de lo social. Lo cual conlleva que el proceso no se desarrolla únicamente en un plano socio-histórico (como en el caso de Lefort) sino entre dicho plano y lo que está por debajo de él y que escapa a la acción humana. La cual ve así limitado su campo de intervención en el planteo de Laclau y Mouffe.
}

${ }^{59}$ Hasta qué punto en la obra de Lefort ellos fungen como densa descripción de lo que realmente sucede en diversas sociedades, o bien como tipos ideales que brindan esquemas conceptuales a partir de los que se penetra en las características profundas de los acaeceres sociales, es una cuestión difícil de resolver que excedería con mucho la problemática que aquí pretendemos abordar. Bástenos decir que, por momentos, la utilización que hace de ellos nos inclina a pensar que los considera como formas empíricas del ser social; sin embargo la «pureza» con la que los describe, cierta unidireccionalidad que deja en un segundo plano las posi- 
como construcciones lógico-conceptuales (que obviamente se elaboran a partir de procesos empíricos pero que no son ellos, sino la acentuación de algunos de sus rasgos en pos de una cierta "pureza») es dable munirnos de ellas para posicionar nuestra mirada de una forma tal que podamos aprehender las características y tendencias que predominan en las diversas esferas sociales y en los procesos en marcha en ellas. Los cuales nunca son completamente democráticos ni completamente totalitarios, no se cae en la pureza de un extremo o del otro, sino que habitamos un complejo y ambiguo entramado de relaciones dialécticas, al que tal vez podamos iluminar parcialmente a través de estos tipos ideales.

Las formas en que la sociedad se estructura, y a las que estos tipos ideales nos permiten acercarnos, constituyen, además, un momento del esfuerzo por captar las particularidades de la acción política -de aquella que se desarrolla en la política pero sobre todo de la que tiene lugar en lo político- que en esas estructuras emergen y que ellas propugnan o desalientan. Por aprehender si el modo más o menos recurrente y establecido en que se desarrollan las relaciones entre los seres humanos en una sociedad particular tiende a acoger la pluralidad o, mejor dicho, hasta qué punto tiende a acogerla y en qué ámbitos y aspectos específicos lo hace. En qué espacios una sociedad, cuyo sistema político se rige por reglas de características democráticas, está abierta a la posibilidad de otros punto de vista sobre lo mismo; más aun: alienta su emergencia por ser esto parte constitutiva de su forma de constituirse. Pregunta que lleva adherida su opuesta: en qué campos o sectores de los mismos predomina la tendencia a rechazar la existencia de perspectivas distintas a la establecida, por lo que cualquier otro será considerado como un enemigo que muestra su relatividad y que, por ende, debe ser eliminado. Cómo y en dónde prevalece, en una misma sociedad, el acogimiento de las divisiones y las diferencias en el interior del plexo relacional, o bien impera la imagen de una homogeneidad para la que todo exterior es una amenaza a ser erradicada.

A esto se agrega que es a través de este mismo entrelazamiento de perspectivas que consideramos posible aprehender las características propias de la acción política (y quizás también de las acciones sociales que tienen lugar en las distintas esferas de la sociedad). Así, si en esta sección nos hemos enfocado en la «residencia común» dentro de la que se desarrollan las acciones humanas, intentaremos ahora dirigir nuestra vista a las acciones políticas mismas y a la lógica que ellas entrañan. ${ }^{60} \mathrm{Y}$ en este punto es fundamental poner en el centro la noción de quiasma elaborada por Merleau-Ponty, junto con la relación de reversibilidad que ella implica; reversibilidad que, como hemos visto, nunca es

bles «contaminaciones» entre ambos, nos lleva a considerar que en algún punto los concibe como complejos tipos ideales, a partir de los cuales reflexionar sobre los acontecimientos empíricos.

${ }^{60}$ De más está decir que la distinción entre la estructura relacional y las acciones que en ella tienen lugar es sólo analítica; pues iría en contra de todo lo que hemos venido sosteniendo el pensarlas como entes aislados, con relaciones que no las imbrican mutuamente. El acento puesto en uno u otro momento es sólo eso, un acento, al que nos obliga el proceso expositivo. 
completa, «siempre inminente y nunca realizada de hecho». ${ }^{61}$ A esto dedicaremos la próxima sección.

\section{Tautología y expresión de lo nuevo}

Hemos comentado ya que, al decir de Merleau-Ponty, habitamos un entramado de interrelaciones en el que cada uno ve lo mismo a su manera, conformándose así un sistema con múltiples entradas en el que las diversas perspectivas se revelan parciales, pues para ellas persiste una zona de opacidad, aunque no para cada una la misma. Son «dos entradas al mismo Ser, accesibles cada una a uno de nosotros únicamente, pero apareciéndole al otro como practicable de derecho»; 62 no puedo ver lo que el otro ve, pero puedo comprenderlo si consigo descentrarme de mi mirada (de mi ego), captando la singular manera en que él centra su visión, aun cuando ella se oponga a la mía. En última instancia esta forma de pensar la relación con el otro (con los otros) entraña aquella weberiana aceptación de una cosmovisión que es negación de la mía y no por ello falsedad. El trasfondo que hace esto posible es lo que Lefort llama la abolición de todo referente último de certeza, la caída del monoteísmo valorativo y con él de la posibilidad de establecer un punto de vista como absoluto, de que haya un piso común que iguale nuestras distintas maneras de ver, en definitiva de que haya un fin para el conflicto en torno a valores. Convivencia de una humana pluralidad de la que surge la imposibilidad de conocer completamente cómo ellos actuarán al relacionarse conmigo y con el mundo que nos enlaza.

Todo lo cual genera una incertidumbre acerca de los otros pero también de mi mismo, en tanto que mi actividad se encuentra hilvanada con la de los otros. Proceso cognitivo que es más bien el de un desconocimiento, como aquel que desata el miedo ilustrado, el cual surge en última instancia de la incertidumbre acerca de si podré conservar mi propia vida, de la autoconservación y su relación con la razón instrumental. Es en este marco que -como hemos visto- se torna racional ceder parte de mi libertad, si los demás se comprometen a su vez a cederla, si ese es el precio de la certeza que desterrará al miedo. Con tal de no soportar la libertad de los otros, dócilmente acepto no soportar la mía y esto «interesa a todos los demás» ${ }^{63}$ (pero en un sentido completamente opuesto al que Merleau-Ponty plantea en el fragmento del que se extrae la cita), pues le brinda también a ellos una certeza: la de su autoconservación. De allí que para el saber ilustrado no pueda haber algo desconocido, no pueda haber una opacidad ni en la naturaleza externa ni en la interna, sea esta última la mía o la de los otros con quienes convivo. Sólo un conocimiento absoluto garantiza una certeza absoluta y con ella la eliminación de lo desconocido, fuente de temor. Por eso el ideal de la ilustración es el sistema, que pretende abarcar con una y la misma lógica todos los aspectos del mundo; sin tener un exterior, pues nada

\footnotetext{
${ }^{61}$ Maurice Merleau-Ponty, Lo visible..., op. cit., p. 183.

62 Idem, p. 109.

${ }^{63}$ Maurice Merleau-Ponty, Las aventuras..., op. cit., p. 259
} 
hay que no sea asimilable por él, ni siquiera el futuro cuyo devenir es algo ya conocido. La existencia de un solo ser que pueda situarse por fuera de esto y verlo desde allí, la mera posibilidad de que esto suceda, es ya iluminar la relatividad de ese sistema que se pretende absoluto; nadie debe tomar la distancia suficiente como para posicionarse en un punto de vista desde el cual se pueda desnaturalizar aquello que se presenta como necesario y eterno.

Es por ello que el saber ilustrado, que es un poder, pierde la capacidad crítica, encerrándose en afirmaciones tautológicas que no son más que silencio, reproducción de lo existente en su forma actual. Pero también por esto la ilustración ejerce un poder, que es un saber, cuyo programa es la eliminación de lo distinto, la totalitaria tendencia a no aceptar un otro como semejante, de hacer de él un enemigo a ser erradicado, pues él es fuente de un temor del cual el ser humano ilustrado quiere librarse, aun al precio de ejercer violencia contra sí mismo. Es como si nos dijese: «en el momento en que voy a tener miedo es cuando empiezo a atemorizar, la agresión que aparto de mí es la misma que envío a otros». ${ }^{64}$

Vemos así el movimiento de una lógica de la reversibilidad que nos lleva de la indeterminación de la acción humana a la acción racional de ceder parte de la libertad de actuar. ${ }^{65}$ Es a partir de dicha lógica que podemos avanzar en nuestras reflexiones en torno a la acción política, sin abandonar ninguno de los trazos que hemos venido bosquejando a lo largo de este escrito. Pues, como hemos intentado mostrar, es dable encontrar en ella una adherencia de opuestos, que no se resuelve en el surgimiento de un tercer término que supera a ambos identificándolos; por el contrario, no hay identificación que diluya las diferencias entre los dos términos, ambos mantienen su oposición en forma aporética.

La palabra que rompe el silencio con su advenimiento no deja de estar rodeada de él, pues sin su presencia ella no diría nada, no habría fondo sobre el cual su advenimiento se tornarse audible; por eso nuestra tarea no se reduce a escuchar la palabra que emerge sino también a «poner al descubierto los hilos de silencio de que está entremezclada». ${ }^{66}$ De la misma forma la acción política (y tal vez toda acción social) entraña simultáneamente una producción de sentido que tiende a (re)producir mecanismos cercanos, en su lógica, a los que conforman el tipo ideal de sociedad totalitaria, y a generar relaciones que tienden a producir un vincularse próximo al que constituye el tipo ideal de sociedad de-

\footnotetext{
${ }^{64}$ Merleau-Ponty, M., «Nota sobre Maquiavelo», en Signos, op. cit., p. 266.

${ }^{65}$ En pos, tal y como señalamos en la sección anterior, de la erección de un sistema cuya tendencia intrínseca es presentarse como absoluto; para el cual, por ende, toda otredad es un principio de relativización que debe ser eliminado, lo que nos lleva a la vida en colectividad en la que nos vinculamos con los demás seres humanos con quienes habitamos ese mismo mundo, entramado de vínculos del que emerge el contexto de pluralidad que produce la indeterminación de la acción y la ausencia de toda certeza, de todo conocimiento último; desconocimiento que es fuente de..., etc.

${ }^{66}$ Maurice Merleau-Ponty, Lenguaje indirecto..., op. cit., p. 57 (la cursiva es nuestra).
} 
mocrática. Es decir que ella porta un sentido de «orden», tendiente al cierre de la pluralidad humana, a marcar límites a la acción (propia y ajena) en pos de evitar que su desarrollo rompa el fatal círculo de la existencia, de la certeza que lo ya completamente conocido brinda. Una dimensión de la acción que es incapaz de expresar algo nuevo, más aun que le hace la guerra a toda novedad pues ella es la figura misma del enemigo, la que con su mero advenimiento atenta contra la estabilidad de unas institucionalizadas formas de interrelacionarnos; que hace de la tautología su modo de ser siendo, que es ser silencio. $Y$ adherido a esto la acción política entraña una tendencia a expresar algo cualitativamente nuevo y como tal desconocido hasta entonces, que rompe ese ruidoso silencio de lo ya sabido, inaugurando sentido; cambiando así (aun cuando el propio agente no tenga plena conciencia de ello, desbordado por su accionar) lo establecido, introduciendo una modificación que impide la reproducción exacta de lo mismo; no es ruptura radical con todo lo anterior sino un tensionar lo existente hacia su transformación, una ruptura del ciclo que posibilita el ingreso de la historia. Un momento de la acción que no es cierre sino abertura y, por ello, es xóos ( $\operatorname{caos}^{67}$ ); abertura de sentido anterior a todo intento de orden sobre ese mismo sentido que esta dimensión caótica de la acción expresa y, al expresarla, la hace existir para nosotros -sacándola de su estado de latencia-, para la pluralidad de puntos de vista que la percibirán cada uno a su manera.

Relación de reversibilidad entre dos dimensiones del mismo ser que, como hemos visto, nunca es completa, se eclipsa antes de realizarse. De la misma forma que el tangente está siempre por ser tocado mas esto no se llega a concretar de hecho, la acción política con su capacidad generativa produce el advenimiento de un nuevo sentido, manifestando su potencialidad instituyente, mas cuando lo nuevo es plenamente incorporado al entramado relacional que habitamos, cuando es instituido, ya no es nuevo. Y este accionar instituido, con su tendencia al cierre, a la no aceptación de lo distinto que debe ser asimilado por él, al asimilarlo, al hacerlo suyo, modifica su estructura para poder incorporarlo, entonces su cierre ya no es completo. Proceso, este último, similar a aquella manera en que se produce el aprendizaje de la lengua, según MerleauPonty. ${ }^{68}$ Se vislumbra así la ambigüedad de la acción política, en permanente movimiento entre dos términos opuestos que se hallan adheridos entre sí; esto es lo que cabe llamar una dialéctica de la acción política que no se resuelve en un término superior, que es intrínsecamente aporética.

Hemos visto que la revolución y su fracaso son la misma cosa, pero también hemos intentado tornar manifiesto que esa lógica propia de una acción política de extrema radicalidad es hallable isomórficamente en la dialéctica interna de acciones políticas menos radicales. Que si hay avance en la historia, que si nos posicionamos en un punto de vista desde el cual se haga visible la estructura de la totalidad y los «progresos» que en ella pueden llegar a existir; no pode-

\footnotetext{
67 Usamos la noción de xáos (caos) en sus dos acepciones, como caos y como abertura; las cuales, desde nuestra perspectiva, constituyen una sola.

${ }^{68}$ Cf. Maurice Merleau-Ponty, Lenguaje indirecto..., op. cit., pp. 49 y ss.
} 
mos dejar de aceptar que «ese progreso se paga con regresiones», 69 que lo adquirido con esfuerzo al inmovilizarse está perdido. La acción humana como expresión primordial implanta un nuevo sentido antes inexistente, pero no se agota allí sino que al mismo tiempo «inaugura un orden, funda una institución, o una tradición». ${ }^{70}$

De allí que al menos un primer paso, para la mirada que no se conforma con este presente y sus miserias, esté en suspender la búsqueda de una acción política solamente generadora, de pensar que vamos a alcanzar una forma de percibir o de expresarnos que sólo tenga por producto algo nuevo, sin lastre alguno del pasado; puro progreso o pura emancipación. Pues para que ello sea posible es necesario resolver la tensión en favor de uno solo de sus polos, es decir: es necesario dejar atrás a la dialéctica, suspendiendo -al menos momentáneamente- su movimiento. ${ }^{71}$ Pero, sobre todo, tendríamos una menor capacidad para iluminar al menos una parte del sentido objetivo de nuestras propias prácticas. Sin embargo, la contraparte de dicha suspensión implica la tarea, para la mirada crítica de su presente, de develar el carácter generativo de la acción en aquellas situaciones en que todo parece negarlo, en que el mundo parece mera reproducción de un enorme sistema burocrático que nos encierra para siempre en su jaula de hierro. Tarea de importancia vital porque percibir ese carácter de la acción (al menos su latencia en ella) es ya darle forma, es cargarlo con el sentido de lo nuevo. $Y$ dicha tarea únicamente puede ser llevada a cabo por una mirada otra, que no haya sido deglutida por esa lógica que no tolera un exterior, que se mantenga crítica, acogiendo la incerteza como un momento de su propio saber (que es un poder), quedando así obligada a mantenerse sobrerreflexiva.

En la voz nueva hay silencio, en las conquistas que arduamente logramos está adherido el obstáculo a nuestra libertad. Ser capaces de ver que aun cuando algunos no se aten a la certeza y se aventuren a lo desconocido, aun cuando soporten su libertad, hay allí también regresión y fracaso. Ser conscientes, en definitiva, que si no hay un fin de la historia que suspenda la política tampoco se puede renunciar a lo que es intrínseco a ella: la lucha.

\footnotetext{
${ }^{69}$ Maurice Merleau-Ponty, Las aventuras..., op. cit., p. 29. Imposible evitar aquí la tentación de citar la conocida aseveración benjaminiana según la cual "no hay documento de cultura que no sea a la vez un documento de barbarie" (Walter Benjamin, Sobre el concepto de historia. Tesis y fragmentos, Buenos Aires, Piedras de papel, 2007, p. 28, las cursivas son nuestras).

${ }^{70}$ Maurice Merleau-Ponty, Lenguaje indirecto..., op. cit., p. 80 (las cursivas son nuestras).

${ }^{71}$ A esto aspira, a nuestro entender, el proyecto de racionalidad comunicativa de Habermas, lo cual se evidencia particularmente en las críticas que les dirige a Horkheimer y Adorno (Cf. Jürgen Habermas, El discurso filosófico de la modernidad, Buenos Aires, Taurus, 1989, especialmente capítulo 5). En efecto, el cuestionamiento central que les realiza es el haber planteado que aquello que posee un potencial emancipador (la razón ilustrada) es a su vez fuente de la regresión a la barbarie; frente a esto, él planteará una razón comunicativa puramente emancipadora y sin lastre alguno de dominación. Pero si dicha razón no ejerce ninguna forma de coacción, tampoco podría ejercer aquella que es producto del mejor argumento (Idem, p. 162), marcándose así un punto ciego del pensamiento habermasiano.
} 


\section{Bibliografía}

(1940) BENJAMIN, Walter, Sobre el concepto de historia. Tesis y fragmentos (Tr. Bolívar Echeverría, 2007), Buenos Aires, Piedras de papel.

(2010) GAMBAROTTA, Emiliano, "La dialéctica aporética entre cuerpo y sí mismo: Una lectura de Dialéctica de la ilustración en clave política", en Intersticios. Revista Sociológica de Pensamiento Crítico, Vol. 4 № 1, ISSN 1887-3898, $<$ http://www.intersticios.es/index>.

(1985) HABERMAS, Jürgen, El discurso filosófico de la modernidad (Tr. Manuel Jiménez Redondo, 1989), Buenos Aires, Taurus.

(1942) HORKHEIMER, Max, “Razón y autoconservación”, en Teoría tradicional y teoría crítica (Tr. José Luís López y López de Lizaga, 2000), Barcelona, Ediciones Paidós e I.C.E. de la Universidad Autónoma de Barcelona.

(1966) HORKHEIMER, Max, Crítica de la razón instrumental (Tr. H. A. Murena y D. J. Vogelmann, 1969), Buenos Aires, Editorial Sur.

(1947) HORKHEIMER, Max y ADORNO, Theodor W., Dialéctica de la ilustración. Fragmentos filosóficos (Tr. Juan José Sanchez, 2001), Madrid, Editorial Trotta.

(1945) MERLEAU-PONTY, Maurice, La fenomenología de la percepción (Tr. Emilio Uranga, 1957), México, Fondo de Cultura Económica, 1957.

(1955) MERLEAU-PONTY, Maurice, Las aventuras de la dialéctica (Tr. León Rozitchner, 1957), Buenos Aires, Leviatán.

(1960) MERLEAU-PONTY, Maurice, Signos (Tr. Caridad Martínez y Grabiel Olivier, 1964), Barcelona, Seix Barral.

(1964) MERLEAU-PONTY, Maurice, Lo visible y lo invisible (Tr. José Escudé, 1967), Madrid, Seix Barral.

(1985) LACLAU, Ernesto y MOUFFE, Chantal, Hegemonía y estrategia socialista (Tr. Ernesto Laclau, 2006), Buenos Aires, FCE.

(1983) LEFORT, Claude, "La cuestión de la democracia", en La incertidumbre democrática (Tr. Esteban Molina, 2004), Barcelona, Anthropos.

(1986) LEFORT, Claude, "Reversibilidad. Libertad política y libertad individual", en La incertidumbre democrática (Tr. Esteban Molina, 2004), Barcelona, Anthropos, 2004.

(1981) LEFORT, Claude, "La lógica totalitaria", en La incertidumbre democrática (Tr. Esteban Molina, 2004), Barcelona, Anthropos.

(1981) LEFORT, Claude, "La imagen del cuerpo y el totalitarismo", en La incertidumbre democrática (Tr. Esteban Molina, 2004), Barcelona, Anthropos.

(1992) LEFORT, Claude, “¿Renacimiento de la democracia?”, en La incertidumbre democrática (Tr. Esteban Molina, 2004), Barcelona, Anthropos.

(1923) LUKÁCS, George, Historia y consciencia de clase (Tr. Manuel Sacristán, 1969), México, Grijalbo.

(2003) PLOT, Martín, El kitsch político, Buenos Aires, Prometeo.

(2008) SCHWARZBÖCK, Silvia, Adorno y lo político, Buenos Aires, Prometeo Libros.

(2003) SCHWARZBÖCK, Silvia, "El reino de los medios", en Deus Mortalis, № 2.

(1918) WEBER, Max, "Parlamento y gobierno en una Alemania reorganizada", en Obras selectas (2003), Buenos Aires, Distal. 
(1919) WEBER, Max, “La política como vocación", en Ciencia y política (1991), Buenos Aires, Centro Editor de América Latina.

(1919) WEBER, Max, “La ciencia como vocación", en Ciencia y política (1991), Buenos Aires, Centro Editor de América Latina.

(1921) WEBER, Max, Economía y sociedad (Tr. José Medina Echevería et al., 1998), México, FCE. 